\title{
Prooxidant-Antioxidant Balance in Umbilical Cord Blood of Infants with Meconium Stained of Amniotic Fluid
}

\author{
Mohammad Hassan Arjmand, ${ }^{1}$ Farhat Ahmad Shah, ${ }^{2}$ Masoud Saleh Moghadam, ${ }^{3}$ \\ Fatemeh Tara, ${ }^{4}$ Amin Jalili, ${ }^{5}$ Mojtaba Mosavi Bazaz, ${ }^{6}$ and Daryoush Hamidi Alamdari ${ }^{7}$ \\ ${ }^{1}$ Department of Biology, School of Sciences, Payame Noor University, Mashhad 91735433, Iran \\ ${ }^{2}$ Neonatal Research Center, Mashhad University of Medical Sciences, Mashhad 9137913316, Iran \\ ${ }^{3}$ Department of Chemistry, School of Science, Payame Noor University, Mashhad 91735433, Iran \\ ${ }^{4}$ Department of Obstetrics and Gynecology, OM-Albanin Hospital, Mashhad University of Medical Sciences, \\ Mashhad 9144663595, Iran \\ ${ }^{5}$ Department of New Science and Technologies, Mashhad University of Medical Sciences, Mashhad 9177948564, Iran \\ ${ }^{6}$ Department of Social Medicine, Faculty of Medicine, Mashhad University of Medical Sciences, Mashhad 9138913131, Iran \\ ${ }^{7}$ Stem Cell and Regenerative Medicine Research Group, Department of Biochemistry, Faculty of Medicine, \\ Mashhad University of Medical Sciences, Mashhad 9177948564, Iran \\ Correspondence should be addressed to Daryoush Hamidi Alamdari; hamidiad@mums.ac.ir
}

Received 15 July 2013; Accepted 2 October 2013

Academic Editor: Vladimir Uversky

Copyright (C) 2013 Mohammad Hassan Arjmand et al. This is an open access article distributed under the Creative Commons Attribution License, which permits unrestricted use, distribution, and reproduction in any medium, provided the original work is properly cited.

\begin{abstract}
Objective. Using a novel assay termed prooxidant-antioxidant balance (PAB) assay to determine prooxidant-antioxidant balance in umbilical cord blood of infants with meconium stained of amniotic fluid (MSAF). Passage of meconium in amniotic fluid is associated with increase of neonatal mortality and morbidity. This complication occurs in about $15 \%$ of infants and is more widespread in postterm neonates. About 1.5 percent of neonates with MSAF develop meconium aspiration syndrome. Method. Sera of 29 umbilical cord blood of infants with MSAF and 32 healthy infants (HI) were collected. Both groups had nonsmoker and nonalcoholic mothers with no diseases. The PAB was measured. Result. There was a significant increase of PAB value $(32.8 \pm 15.9 \mathrm{HK})$ in umbilical cord blood of infants with MSAF in comparison to HI $(24.5 \pm 12.6 \mathrm{HK})(P<0.05)$. There was no significant correlation between PAB value and age of mothers. Conclusion. The increased PAB value in infants with MSAF showed that these infants are exposed to oxidative stress. Further research with larger population is needed to demonstrate the oxidative stress in infants with MSAF.
\end{abstract}

\section{Introduction}

Meconium is composed of desquamated cells from the intestine and skin, gastrointestinal mucin, lanugo hair, fatty material from the vernix caseosa, amniotic fluid, and intestinal secretions. It also contains blood group-specific glycoproteins, biliary acids (cholic, chenodeoxycholic, deoxycholic, and lithocholic), copper, zinc, magnesium, calcium iron, phosphorus, and plasma proteins such as alphal-antitrypsin and phospholipase A2. Black-green color of meconium is due to the presence of bile pigments $[1,2]$. Expulsion of meconium from the intestinal lumen into the amniotic cavity is a consequence of increased intestinal peristalsis and of anal sphincter relaxation resulting from vagal stimulation [3].

Meconium-stained amniotic fluid (MSAF) can cause mechanical obstruction of airways and pulmonary air leak, pneumonitis, vasoconstriction of pulmonary vessels, and inactivation of surfactant effect which could result in pulmonary inflammation and apoptosis. $7 \%$ to $20 \%$ of deliveries at term have meconium in the amniotic fluid, which would reach to $40 \%$ in postterm deliveries [4]. $5 \%$ of infants born through MSAF develop meconium aspiration syndrome (MAS) which is a real threat to many newborns worldwide, with a case fatality rate of $5 \%$ (as much as $40 \%$ ), in addition 
to MAS short- and long-term pulmonary and neurodevelopmental sequelae which could occur $[5,6]$.

In human, there are the numerous prooxidants (POX) and antioxidants $(\mathrm{AO})$, and a delicate balance between the production and the elimination of POX is maintained. Oxidative stress (OS) is defined as an imbalance between POX and $\mathrm{AO}$ in favor of POX. POX $\left(\mathrm{O}_{2}{ }^{-}, \mathrm{H}_{2} \mathrm{O}_{2}, \mathrm{OH}^{-}\right.$, etc. $)$derive either from metabolic processes or from external sources and can potentially react with the body's own molecules. AO mop up the excess amount of the POX before they damage the essential molecules. AO consists of the soluble antioxidants (vitamin C, urate, etc.), the lipid soluble antioxidants (vitamin $\mathrm{E}, \mathrm{A}$, etc.), and the enzymatic antioxidants (catalase, peroxidase, dismutase, etc.) [7].

The concentration of either POX or AO can be measured one by one in separate individual assays. For example, Ochi and Cutler invented a diagnostic plot derived from the measurement of 82 assays which characterize both the oxidative stress and the antioxidant profile [8]. However, the effect of the prooxidant or the antioxidant molecules in serum is an additive effect which could lead to incorrect measurements. Consequently, various methods have been developed in order to measure the total oxidants (such as TOC and TOS assays) or antioxidants (such as FRAP and ORAC assays), separately. In this context, PAB assay is developed to measure the balance of oxidants and antioxidants simultaneously in one experiment and give a redox index $[7,9,10]$.

Growing evidence indicates that chronic and acute overproduction of POX under pathophysiologic conditions is unifying mechanism for tissue damage and cell apoptosis. A few studies showed that there is an oxidative stress in MSAF, but more studies using different methods are needed to substantiate the PAB in MSAF.

To the best of our knowledge, this is the first time that the prooxidant-antioxidant balance is measured in umbilical cord blood of infants with MSAF.

\section{Methods}

2.1. Chemicals. TMB powder $\left(3,3^{\prime}, 5,5^{\prime}\right.$-Tetramethylbenzidine, Fluka), peroxidase enzyme (Applichem: $230 \mathrm{U} / \mathrm{mg}$, A3791, 0005, Darmstadt, Germany), chloramine T trihydrate (Applichem: A4331, Darmstadt, Germany), hydrogen peroxide (30\%) (Merck). Molecular biology grade reagents were used, and preparations were done in double distilled water.

2.2. Subjects. Sera of 29 umbilical cord blood of infants with MSAF and 32 healthy infants were collected. Collection of samples was done from July to December in 2013. Both groups had nonsmoker and nonalcoholic mothers without any special diseases. The PAB was measured. The study protocol was approved by the Ethics Committee for Clinical Research of the Mashhad University of Medical Sciences (MUMS).

2.3. Collection of Serum. Blood samples from each subject were collected from infant's umbilical cord and then sent to the laboratory for serum separation. Samples were centrifuged at $1500 \mathrm{~g}$ for $15 \mathrm{~min}$ at room temperature to obtain serum. Hemolytic samples were excluded from analysis. Sera were stored at $-80^{\circ} \mathrm{C}$.

2.4. Method. The PAB assay is the only available test that can measure the balance of oxidants and antioxidants simultaneously in one experiment. It uses two different kinds of reactions: one is an enzymatic reaction where the chromogen TMB is oxidized to a color cation by peroxides and the second is a chemical reaction where the TMB cation is reduced to a colorless compound by antioxidants $[7,8,11]$. The photometric absorbance is then compared with the absorbances given by a series of standard solutions that are made by mixing varying proportions $(0-100 \%)$ of hydrogen peroxide with uric acid [7]. A low PAB value means that antioxidants are present at greater concentration than oxidants, while a high PAB value means more oxidants are present than antioxidants. The standard solutions were prepared by mixing varying proportions $(0-100 \%)$ of $250 \mathrm{mM}$ hydrogen peroxide with $3 \mathrm{mM}$ uric acid (in $10 \mathrm{mM} \mathrm{NaOH}$ ). The TMB powder $(60 \mathrm{mg})$ was dissolved in $10 \mathrm{~mL}$ DMSO. For preparation of the TMB cation solution, $400 \mathrm{~mL}$ of the TMB/DMSO solution was added to $20 \mathrm{~mL}$ of acetate buffer (0.05 $\mathrm{M}$ buffer, $\mathrm{pH} 4.5)$, and then $70 \mathrm{~mL}$ of fresh chloramine $\mathrm{T}(100 \mathrm{mM})$ solution was added. The solution was mixed well and incubated for 2 hours at room temperature in a dark place, and then $25 \mathrm{U}$ of peroxidase enzyme solution was added. This mixture was dispensed into $1 \mathrm{~mL}$ aliquots and stored at $-20^{\circ} \mathrm{C}$. The TMB solution was prepared by adding $200 \mu \mathrm{L}$ TMB/DMSO to $10 \mathrm{~mL}$ of acetate buffer $(0.05 \mathrm{M}$ buffer, $\mathrm{pH} 5.8)$ and the working solution was prepared by mixing $1 \mathrm{~mL}$ TMB cation solution with $10 \mathrm{~mL}$ TMB solution. This working solution was incubated for $2 \mathrm{~min}$ at room temperature in a dark place and immediately used. Ten microliters of each sample, standard, or blank (distilled water) were mixed with $200 \mu \mathrm{L}$ of working solution in each well of a 96-well plate, which was then incubated in a dark place at $37^{\circ} \mathrm{C}$ or $12 \mathrm{~min}$. At the end of incubation, $100 \mu \mathrm{L}$ of $2 \mathrm{~N} \mathrm{HCl}$ was added to each well, and the optical density (OD) was measured with an ELISA reader at $450 \mathrm{~nm}$, with a reference wavelength of 620 or $570 \mathrm{~nm}$. A standard curve was generated from the values of the standard samples. The values of the PAB assay are expressed in arbitrary units, based on the percentage of hydrogen peroxide in the standard solution. The values of the unknown samples were then calculated based on the values obtained from the generated standard curve.

\section{Statistics}

The Statistical Package for the Social Sciences (SPSS) version 16.0 was used for statistical analysis. All parameters were given as mean \pm S.D. The group comparisons were assessed by the independent $t$-test and also Pearson correlation was used for correlation of age and $\mathrm{PAB}$ value. The significance level was considered less than 0.05 with a confidence interval of $95 \%$.

\section{Results}

The PAB values of HI group and MSAF group were 24.5 \pm 12.6 (HK unit) and $32.8 \pm 15.9$ (HK unit), respectively (Figure 1). 


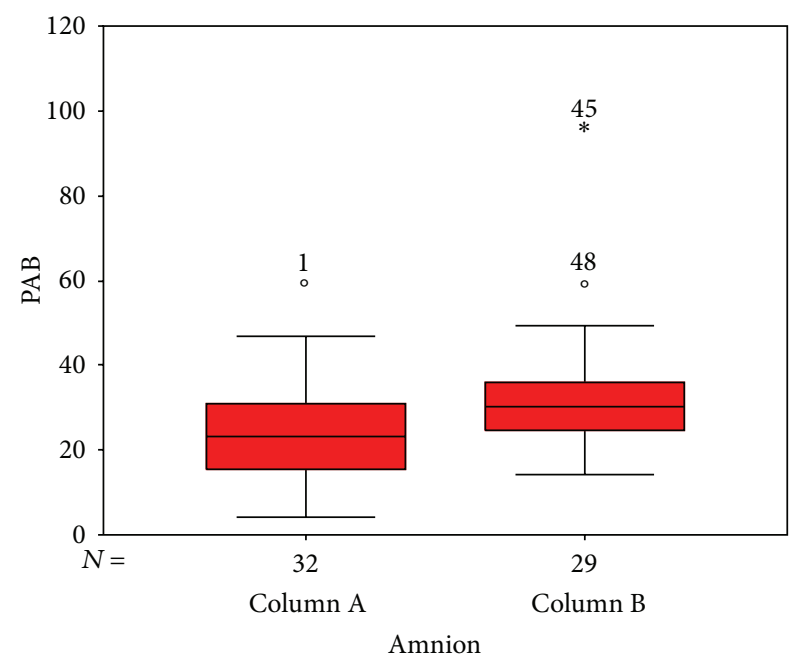

FIgURE 1: PAB value in HI group (column A) and MSAF group (column B). (Mean and the standard error/standard deviation of $\mathrm{PAB}$ value.)

HK is an arbitrary unit used by inventors of PAB method (Hamidi and Koliakos) [7]. There was a significant difference $(P$ value $=0.027)$ between the PAB value of the HI group and the MSAF group. There was no significant correlation between $\mathrm{PAB}$ value and the age of mothers (Table 1).

\section{Discussion}

In this study, we showed that there is an increased OS in umbilical cord blood of infants with MSAF in comparison to healthy group using a novel method called PAB assay.

There are two prevailing theories about mechanism of meconium passage in amniotic fluid at term and postterm infants: one is that normal maturation of the gastrointestinal tract results in meconium passage, the other is that pathologic processes such as stress via hypoxia or some infection in fetus can trigger meconium passage. Previous studies have showed an increased OS in hypoxic fetuses and neonates with elevated products of lipid peroxidation in expired air, serum malondialdehyde, serum isoprostanes, serum total hydroperoxides, advanced oxidative protein products, and increased nonprotein bound iron in serum. Low levels of antioxidants have also been observed in red blood cells [12, 13].

Just one study showed that infants with MSAF have high concentration of 8-iso-prostaglandin F2alpha in neonatal cord blood, as a marker of lipid oxidation, and suggests that these infants were exposed to OS [14].

It is demonstrated that there is an increased level of proinflammatory cytokine such as IL-1 $\beta$, IL-6, tumor necrosis factor (TNF)- $\alpha$, and IL-8 in newborns with MASF [15]. In the other hand, there is a strong correlation between proinflammatory cytokine and OS in various diseases such as cardiovascular disease [16], diabetes mellitus [17], inflammatory bowel disease [18], obesity [19], Alzheimer [20], and alcoholic liver disease [21]. OS can cause increasing cytokine production by many different mechanisms. The increased POX
TABLE 1: Age of mothers and PAB value in MSAF and control group.

\begin{tabular}{lccc}
\hline Group & $\begin{array}{c}\text { Ages of mothers } \\
\text { (years) }\end{array}$ & $\begin{array}{c}\text { Number of } \\
\text { mothers }\end{array}$ & $\begin{array}{c}\text { PAB value } \\
\text { (HK unit) }^{* *}\end{array}$ \\
\hline MSAF & $26 \pm 5.6$ & 29 & $32.8 \pm 15.9$ \\
Control & $25.8 \pm 4.4$ & 32 & $24.5 \pm 12.6$ \\
\hline
\end{tabular}

${ }^{*}$ No significant difference between ages of mothers; ${ }^{* *}$ significant difference between PAB values $(P<0.05)$.

levels, acting similar second messengers, are well known to mediate inflammatory signaling by activating various protein kinases such as JNK, PI3 K, PKC, and PLC. These kinases could stimulate redox sensitive transcription factors such as STAT, CREB, NF- $\kappa$ B, AP-1, NFAT, and ATF2 via a series of signaling events transduced by other kinases like MAPK, ERK, and JAK. The activation of transcription factors leads to the transcriptional activation of inflammatory cytokines (TNF $\alpha$, IL-1, IL-6, IL-8, IL-18, etc.), chemokines (chemoattractant protein-1, etc.), and growth factors (transforming growth factor- $\beta$, monocyte, connective tissue growth factor, etc.) which could amplify inflammatory complications via autocrine and paracrine pathways [22]. In addition, it is demonstrated that antioxidants can downregulate the proinflammatory cytokines through two possible mechanisms; firstly, through their effect on transcription factors that are regulated by redox status, and secondly by influencing PGE2 synthesis, which plays a key role in Th1 response and regulation of proinflammatory cytokines [23]. Therefore, it is reasonable to conclude that proinflammatory cytokine and OS could interact and provoke each other and contribute to the development and progression of some disease.

Our early results showed that infants with MSAF are exposed with OS. However, larger population is needed to confirm these early results. In addition to that, further research will be necessary to precisely determine the correlation between proinflammatory cytokines and OS in infants with MSAF.

\section{Abbreviations}

AP1: Activator protein 1

JNK: c-Jun N-terminal kinase

PI3K: Phosphatidylinositol 3-kinase

NF- $\kappa$ B: Nuclear factor- $\kappa$-binding protein

MAPK: Mitogen-activated protein kinase

PKC: Protein kinase C

PLC: Phospholipase C

ERK: Extracellular signal-regulated kinases

JAK: Janus kinase

STAT: Signal transducer and activator of transcription

NFAT: Nuclear factor of activated T-cells

ATF: Activating transcription factor

PGE2: Prostaglandin E2

IL2: Interleukin-2

CREB: cAMP response element-binding protein

TNF $\alpha$ : Tumor necrosis factor alpha

PGE2: Prostaglandin E2 
TOC: Total oxidant capacity

TOS: Total oxidant status

FRAP: The ferric reducing ability of plasma

ORAC: Oxygen radical absorbance capacity.

\section{Acknowledgments}

The authors thank the Vice Chancellor for Research of Mashhad University of Medical Sciences for funding and supports. This paper is the outcome of the MS thesis of Mohammad Hassan Arjmand (Master of biochemistry, Department of Biology, School of Sciences, Payam Noor University, Mashhad, Iran). The authors thank Mrs. Afsharpour and Mrs. Nasoti for their collaboration in this study.

\section{References}

[1] S. Rapoport and D. J. Buchanan, "The composition of meconium: isolation of blood-group-specific polysaccharides. Abnormal composition of meconium in meconium ileus," Science, vol. 112, no. 2901, pp. 150-153, 1950.

[2] R. H. Côté and J. P. Valet, "Isolation, composition and reactivity of the neutral glycoproteins from human meconiums with specificities of the $\mathrm{ABO}$ and Lewis systems," Biochemical Journal, vol. 153, no. 1, pp. 63-73, 1976.

[3] E. H. Hon, Modern Trends in Human Reproductive Physiology, Butterworth \& Co., London, UK, 1963.

[4] F. C. Miller and J. A. Read, "Intrapartum assessment of the postdate fetus," American Journal of Obstetrics and Gynecology, vol. 141, no. 5, pp. 516-520, 1981.

[5] T. E. Wiswell, "Advances in the treatment of the meconium aspiration syndrome," Acta Paediatrica, vol. 90, no. 436, pp. 28-30, 2001.

[6] G. M. Cleary and T. E. Wiswell, "Meconium-stained amniotic fluid and the meconium aspiration syndrome: an update," Pediatric Clinics of North America, vol. 45, no. 3, pp. 511-529, 1998.

[7] D. H. Alamdari, K. Paletas, T. Pegiou, M. Sarigianni, C. Befani, and G. Koliakos, "A novel assay for the evaluation of the prooxidant-antioxidant balance, before and after antioxidant vitamin administration in type II diabetes patients," Clinical Biochemistry, vol. 40, no. 3-4, pp. 248-254, 2007.

[8] H. Ochi and R. G. Cutler, "Use of oxidative stress diagnostic plot as a health indicator for assessing oxidative stress and its control in humans," United States Patent, 6569683 B1, 2003, http://patft.uspto.gov/netahtml/PTO/search-bool.html.

[9] O. Erel, "A new automated colorimetric method for measuring total oxidant status," Clinical Biochemistry, vol. 38, no. 12, pp. 1103-1111, 2005.

[10] O. Erel, "A novel automated method to measure total antioxidant response against potent free radical reactions," Clinical Biochemistry, vol. 37, no. 2, pp. 112-119, 2004.

[11] D. H. Alamdari, M. Ghayour-Mobarhan, S. Tavallaie et al., "Prooxidant-antioxidant balance as a new risk factor in patients with angiographically defined coronary artery disease," Clinical Biochemistry, vol. 41, no. 6, pp. 375-380, 2008.

[12] L. Ciccoli, V. Rossi, S. Leoncini et al., "Iron release in erythrocytes and plasma non protein-bound iron in hypoxic and non hypoxic newborns," Free Radical Research, vol. 37, no. 1, pp. 51$58,2003$.
[13] G. Buonocore, S. Zani, S. Perrone, B. Caciotti, and R. Bracci, "Intraerythrocyte nonprotein-bound iron and plasma malondialdehyde in the hypoxic newborn," Free Radical Biology and Medicine, vol. 25, no. 7, pp. 766-770, 1998.

[14] B. Y. Liu, C. C. Wang, T. K. Lau et al., "Meconium-stained liquor during labor is associated with raised neonatal cord blood 8-iso-prostaglandin F2 $\alpha$ concentration," American Journal of Obstetrics and Gynecology, vol. 192, no. 1, pp. 289-294, 2005.

[15] A. J. De Beaufort, A. C. Bakker, M. J. D. Van Tol, B. J. Poorthuis, A. J. Schrama, and H. M. Berger, "Meconium is a source of proinflammatory substances and can induce cytokine production in cultured A549 epithelial cells," Pediatric Research, vol. 54, no. 4, pp. 491-495, 2003.

[16] Y. Mizuno, R. F. Jacob, and R. P. Mason, "Inflammation and the development of atherosclerosis-effects of lipid-lowering therapy," Journal of Atherosclerosis and Thrombosis, vol. 18, no. 5, pp. 351-358, 2011.

[17] E. T. De Lemos, J. Oliveira, J. P. Pinheiro, and F. Reis, "Regular physical exercise as a strategy to improve antioxidant and anti-inflammatory status: benefits in type 2 diabetes mellitus," Oxidative Medicine and Cellular Longevity, vol. 2012, Article ID 741545, 15 pages, 2012.

[18] H. Zhu and Y. R. Li, "Oxidative stress and redox signaling mechanisms of inflammatory bowel disease: updated experimental and clinical evidence," Experimental Biology and Medicine, vol. 237, no. 5, pp. 474-480, 2012.

[19] B. Tran, S. Oliver, J. Rosa, and P. Galassetti, "Aspects of inflammation and oxidative stress in pediatric obesity and type 1 diabetes: an overview of ten years of studies," Experimental Diabetes Research, vol. 2012, Article ID 683680, 7 pages, 2012.

[20] F. De Oliveira, C. A. Veloso, J. A. Nogueira-Machado et al., "Ascorbic acid, alpha-tocopherol, and beta-carotene reduce oxidative stress and proinflammatory cytokines in 7 mononuclear cells of Alzheimer's disease patients," Nutritional Neuroscience, vol. 5, no. 2, pp. 148-156, 2012.

[21] A. Ambade and P. Mandrekar, "Oxidative stress and inflammation: essential partners in alcoholic liver disease," International Journal of Hepatology, vol. 2012, Article ID 853175, 9 pages, 2012.

[22] K. V. Ramana, "Aldose reductase: new Insights for an old enzyme," Biomolecular Concepts, vol. 2, no. 1-2, pp. 103-114, 2011.

[23] S. N. Han and S. N. Meydani, "Antioxidants, cytokines, and influenza infection in aged mice and elderly humans," Journal of Infectious Diseases, vol. 182, no. 3, supplement 1, pp. S74-S80, 2000 . 

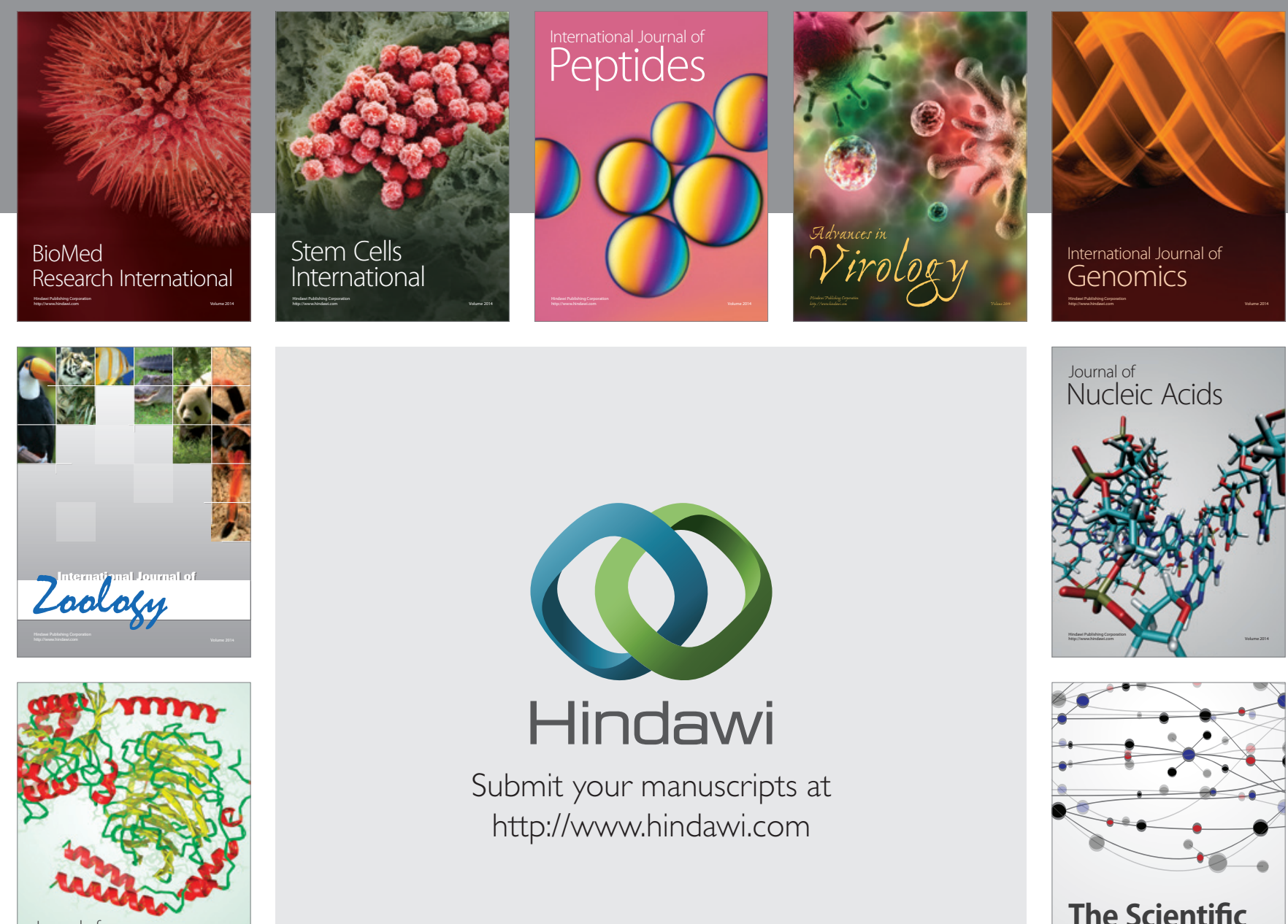

Submit your manuscripts at

http://www.hindawi.com

Journal of
Signal Transduction
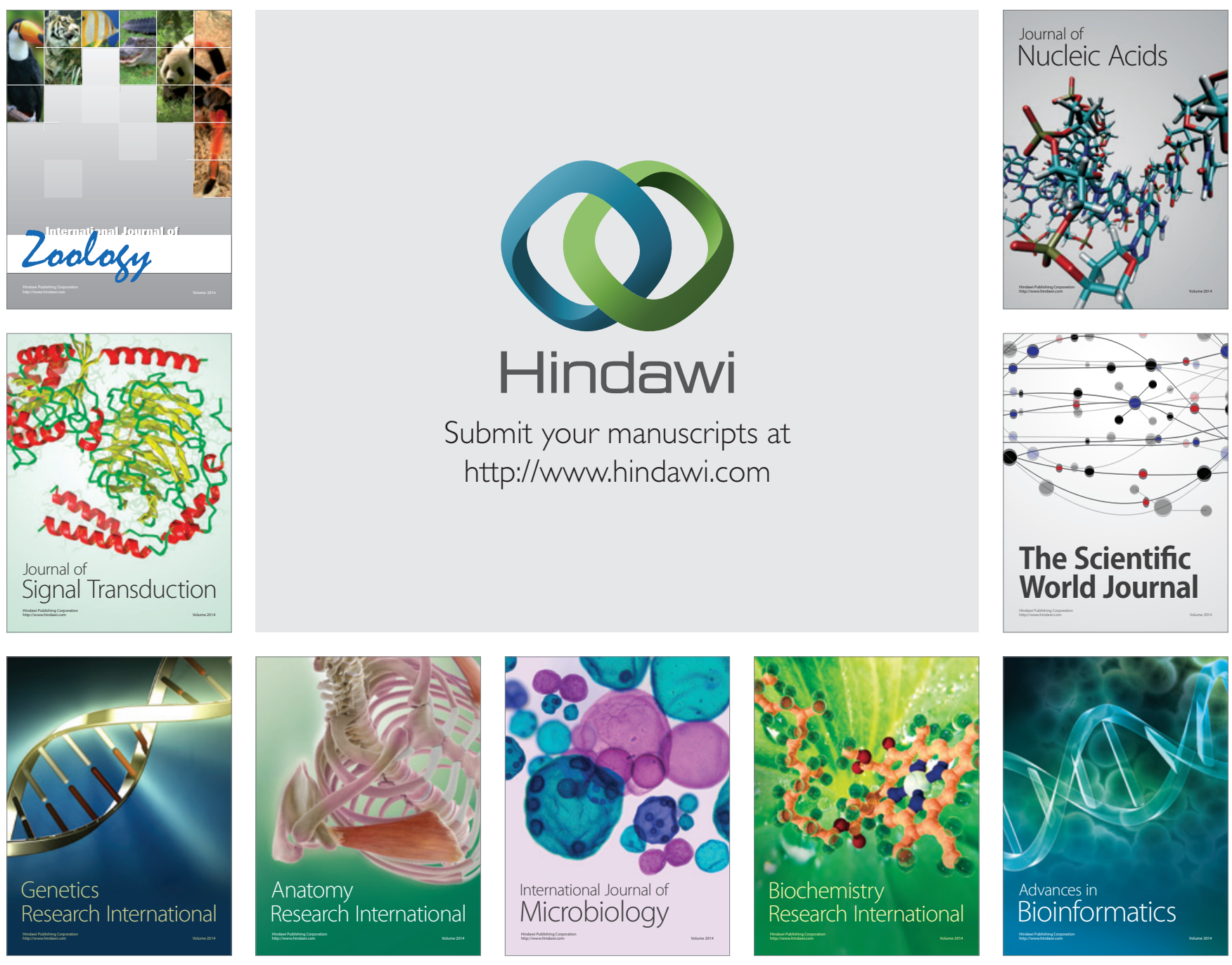

The Scientific World Journal
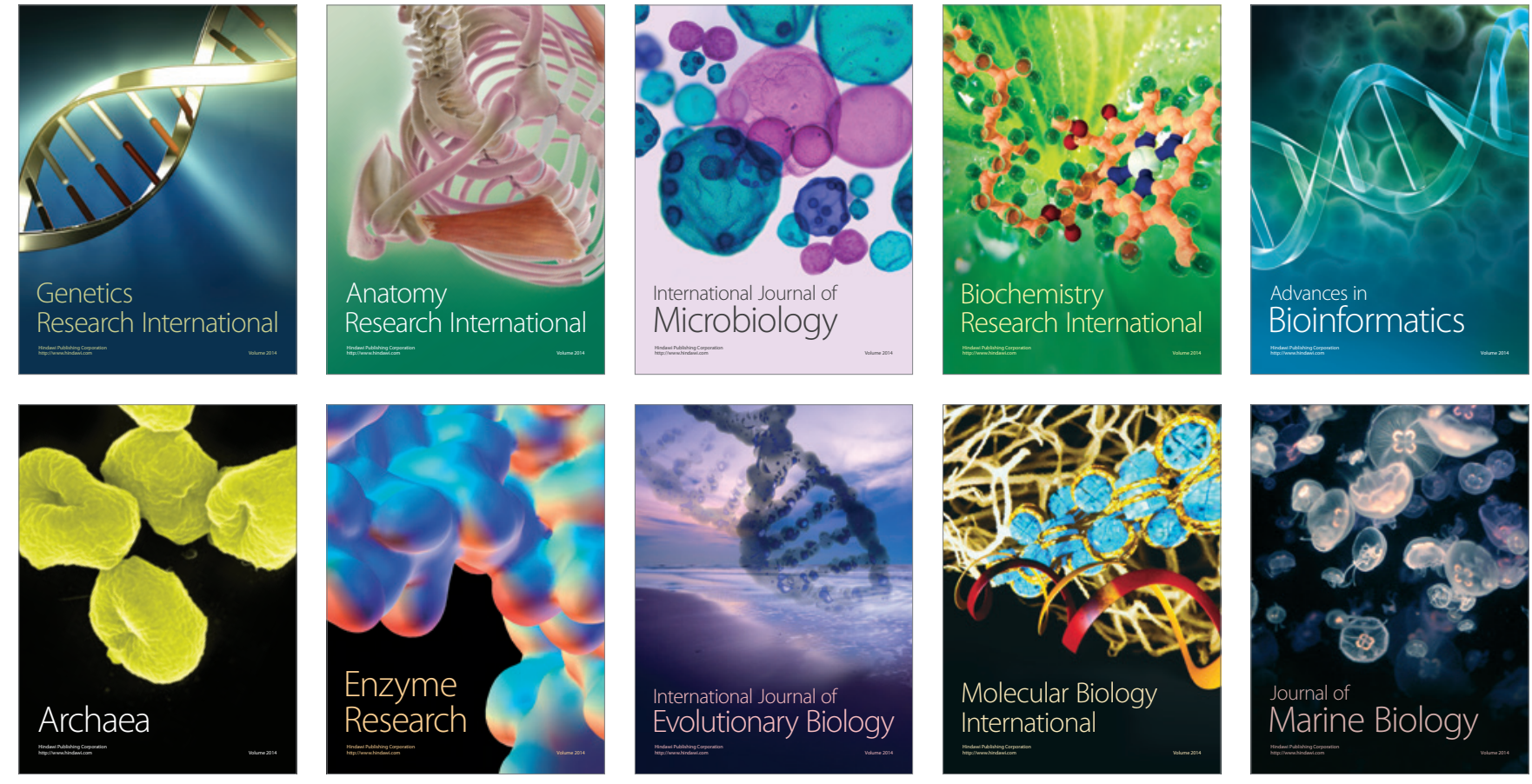